\title{
Commentary on Leigh VanHandel's 'National Metrical Types in Nineteenth Century Art Song'
}

\author{
WILLIAM THOMSON \\ Music School, University of Southern California
}

\begin{abstract}
ASTRACT: Leigh VanHandel's study of metrical locations or phrase beginnings and endings in art songs of the 19th century provides a glance into one property of lyric settings unstudied before. Its fastidious data can be trusted, and yet the study's hard relevance to matters of musical substance, matters of import to a song's perception, is questionable.
\end{abstract}

Submitted 2009 December 6; accepted 2009 December 8.

KEYWORDS: metric locations, art songs, $18^{\text {th }}$ and $19^{\text {th }}$ century, barring, phrasing

LEIGH VanHandel's (2009) study is a careful extension of seminal work done by both William Rothstein and David Huron, all products of the flair for statistical representations that began to invade some pockets of musicology in the late 1960s. It is carefully wrought; it attends to the details of where metric beginnings and endings of lyrics occur within the song oeuvre of prized composers from our history. I find no reason to question that it exposes precise answers for the questions raised about comparative results within the repertoire studied. In this sense, it is exemplary empiricism.

But a major problem looms large, a problem that must be faced now or later. What is counted is assumed to be of significance. But as with many such data-based studies of music, a careful reading by an experienced listener leads to a single daunting question: "So what?" Will these fastidiously derived facts-and there appears to be no reason to doubt their factuality - prove to be relevant to the perception of music? VanHandel implies that such beginning/ending placements reflect both cultural and musical demarcations of potential significance. And yet, where within a metrical scansion a text begins and where it ends are two of the least pertinent perceptual qualities that dominate a listener's ingestion of a song.

There are too many more pressing details—even of a metric nature-to be pursued; a complexity of foreground and background issues that loom large in the sonic context to render those beat-line matters pertinent. That a composer has skillfully fit a lyric to accentual patterns is foremost; that those accentual patterns are couched within appropriate contoural, loudness, timbral, and harmonic properties, control the listener's absorption of musical/lexical context. The exact inter-measure location of where that setting begins and ends is at best trivial. Like much lore of $20^{\text {th }}$ century Serialism, it equates music's notational representation with music's sonic reality. In this it errs.

Observing a difference in phrase beginnings within nationalities, the author observes that "this is not a characteristic that can be used to distinguish French and German composers from one another" (VanHandel, 2009, p. 142). I would suggest that her conclusion can be broadened considerably. If, for instance, French composer Augusta Holmes favored phrase beginnings typical of German composers, that fact is an unlikely definer of her 'style', something that makes her songs 'sound like' the German product. That singular attribute, unless reinforced by similarities of other matters-harmonic, melodic, rhythmic, loudness levels, et al. — bears no defining role for the musical experience. And further, it is interesting that Beethoven songs in compound duple meters reveal quite different points of phrase beginnings from those of Fauré. But whether this fact poses a pertinent stylistic marker for each of the two is a most dubious question. My pre-facto guess is that it will not.

VanHandel states that "the conception of meter continued to change throughout the $19^{\text {th }}$ century. .." (2009, p. 144). This suggestion strikes me as yet another case of the old Music-as-Evolution mismeme that has beset musicology for the past century. It is implausible that Beethoven's sense of $6 / 8$ meter was different from Dave Brubeck's; all evidence suggests that Haydn's feeling for $2 / 4$ was the same as John Philip Sousa's. The human conception of meter, as a basic musical ingredient, has not changed since there was any objectification of a measured time span consisting of accented and unaccented pulses. And thus I am left with yet another case of wonderment: "What kind of metric evolution transpired, 18th- or 19th- or 20th-century?" It is true that meters such 
as $5 / 8$ and $7 / 4$ were not commonplace during those earlier eras, but even in the $20^{\text {th }}$ and $21^{\text {st }}$ centuries they still consisted of time units divided by accented and unaccented pulses. The 'conception of meter' did not change during those 300 years.

In conclusion, it is my opinion that Professor VanHandel's study is an unfortunate extension of the 'information theory' malaise that crept into some areas of academic life late in the previous century, with its appended canon that all information is of equal value. One must only count the grains of sand to arrive at knowledge. This is yet another prime example of that fable's flawed basis, further confirmation of Arthur Koestler's conclusion that statistics can be like a bathing suit: what they reveal is provocative; what they conceal is crucial.

\section{REFERENCES}

VanHandel, L. (2009). 'National metric types in Nineteenth Century art song', Empirical Musicology Review, 4(4), 134-145. 